\title{
Universiteit
}

Leiden

The Netherlands

\section{Dependent attachment: B-4 children in the strange situation}

IJzendoorn, M.H. van; Goossens, F.A.; Kroonenberg, P.M.;

Tavecchio, L.W.C.

\section{Citation}

IJzendoorn, M. H. van, Goossens, F. A., Kroonenberg, P. M., \&

Tavecchio, L. W. C. (1985). Dependent attachment: B-4 children in the strange situation. Psychological Reports, 57, 439-451.

Retrieved from https://hdl.handle.net/1887/11651

Version: $\quad$ Not Applicable (or Unknown)

License: $\quad$ Leiden University Non-exclusive license

Downloaded from: $\quad$ https://hdl.handle.net/1887/11651

Note: To cite this publication please use the final published version (if applicable). 


\title{
DEPENDENT ATTACHMENT: B-4 CHILDREN IN THE STRANGE SITUATION ${ }^{1}$
}

\author{
M. H. VAN IJZENDOORN, ${ }^{2}$ F. A. GOOSSENS \\ P. M. KROONENBERG, L. W. C. TAVECCHIO \\ University of Leiden
}

\begin{abstract}
Summary.-Over the past 15 years the status of the B4 category in Ainsworth's classification system for the Strange Situation has remained unclear, especially as regards the question whether it belongs to the $\mathrm{B}$ or the $\mathrm{C}$ category. As 22 of a sample of 136 Dutch children were classified as B4, their behavior could be analysed in some detail. This resulted in a characterization of B4children whom we propose to call 'dependently attached'. The borderline status or hybrid character of the group was confirmed as the B4-children have many reactions similar to those of $\mathrm{C}$-children but differ from them in showing less resistant behavior.
\end{abstract}

Since Ainsworth and Wittig (1969) applied the well-known "Strange Situation" procedure for the first time to measure the quality of the attachment relationship between caregiver and child, a fair amount of validation research has been carried out; for reviews see Ainsworth, Blehar, Waters, and Wall (1978) and Lamb, Thompson, Gardner, Charnow, and Estes (1984). However, the status of one of the eight attachment patterns in the classification system, i.e., the B4 category, has remained unsertled. 'B4' indicates a formal position within the securely attached group (' $B$ '), adjoining the anxiously-resistant category ('C'). Ainsworth, et al. (1978) claimed that Bell (1970) suggested creating the B4 category when three children of her sample of 33 appeared to be much more frightened in the Strange Situation than the rest of the B-children, although their mothers seemed to be as sensitive as mothers of other B-children. In the behavior of the B4-children there appeared to be remnants of fear acquired during a more or less serious separation from which the B4-children seemed to be recovering slowly.

Bell herself, however, did not report this in her 1970 article, nor did she refer to the status of the B4-category in her article. Nevertheless, B4 became a pointed but unsettled element in the classification system. For more than fifteen years, B4 has been assigned a 'borderline status' (Ainsworth, et al., 1978), pending the final settlement through research into its specific characteristics compared to adjoining groups.

\footnotetext{
Parts of this paper were presented at the International Conference on Infant Studies, New York, 1984. Preparation of this article was supported in part by the Nationaal Comité Kinderpostzegels to Frits Goossens. We gratefully acknowledge the assistance of Jan Swaan in the data collection.

${ }^{2}$ Requests for reprints should be sent to Marinus $H$. van IJzendoorn, Department of Education, University of Leiden, PO Box 9507, 2300 RA Leiden, The Netherlands.
} 
Several researchers do not count the B4-children as a securely attached group (Connell, 1977; Hazen \& Durrett, 1982; Sagi, Lamb, Lewkowicz, Shoham, Dvir, \& Estes, in press). They solve the problem of the borderline status by removing the B4-children from the sample or by combining them with the anxiously resistant category $\mathrm{C}$. Such a solution is at variance with the classification system, but virtually no evidence has been produced to justify this strategy. The main reason for the uncertainty about B4-children was that their small numbers precluded a thorough investigation of their characteristics.

Cross-cultural research could show a way out of this difficulty. The distribution of children over the attachment categories usually differs by culture. In preliminary research it was shown that in the Netherlands a relatively large number of children could be classified as B4 (Van IJzendoorn, Tavecchio, Goossens, Vergeer, \& Swaan, 1983). It seems possible to describe the behavior of the B4 category in some detail and to telate it to some relevant external variables. This should then lead to an exact description of the status of $\mathrm{B} 4$ in the classification system and to some hypotheses concerning its background.

In a preliminary study $(n=66)$, mothers of B4-children seemed to perceive their children as relatively anxious in somewhat stressful situations, such as daily separations, a strange environment, or a strange visitor. In the maternal perception, B4-children differed very much from the other securely attached children in this respect. The question arose whether the B4 category could justifiably be subsumed under the securely attached group, especially in view of their anxious behavior in daily recurring but stressful situations (Van IJzendoorn, et al., 1983).

In this study on the behavior of 136 mother-child pairs in the Strange Situation, we tried to answer this question. More specifically, we wanted to describe the similarities and differences between the B4 category and the other $\mathrm{B}$ categories on interactive behavior towards the mother and the stranger during the Strange Situation and on exploratory behavior in all episodes of the procedure. We hypothesized that children in the B4 category behave much more anxiously than the other B-children and explore a strange environment minimally, irrespective of the presence of the caregiver.

\section{METHOD}

\section{Subjects}

In this study 136 mother-child pairs participated. Many pairs were recruited from day care centers so that the percentage of working mothers in this sample is much higher than in the Dutch population (35\% vs $15.7 \%$ ). The mean age of the children was $21 \mathrm{mo}$; the range was 12 to 25 mo; the mean age of the mothers was $30.16 \mathrm{yr}$. All mothers were either married or living with a partner except one. The socioeconomic status of the families participating ( $M$ 3.88; SD 1.64; 5 missing cases) was determined according to an occupational index currently used in the Netherlands (Van Westerlaak, 
Kropman, \& Collaris, 1975), in which occupational level is scored on a scale extending from unskilled labor (1) to high-level and academic occupations (6). The relationship between attachment and age, sex of child, and socioeconomic status is planned for discussion in a separate manuscript. ${ }^{3}$

\section{Procedure}

The Strange Situation.-The Strange Situation procedure was carried out as described in Ainsworth, et al. (1978), videorecorded, and coded afterwards. The children could only participate if they had not been ill during the last two weeks or had not experienced other drastic changes in their functioning.

The Strange Situation is a very complicated observation procedure; it is not only difficult to reach an acceptable level of intercoder-reliability but also the interinvestigator-reliability can easily be questioned. In his criticism of the Thompson, Estes, and Lamb (1982) reseatch Waters recently (1983) referred to the possibility of consistently different measurements of attachment across studies. To calibrate the procedure with the work of Ainsworth or Main might be a solution.

Such an argument has rather dangerous methodological implications, since it could be used as a strategy to forestall any criticism. Every time an unexpected outcome is reported, the application of the procedure can be blamed, thereby discrediting the results. Especially in cross-cultural research this strategy may lead to a confusion of tongues. If the argument is valid, it points to a fundamental shortcoming of the classification instructions. If these instructions have been clearly written out in sufficient detail, there is little chance of systematic deviations from the standard procedure actoss studies.

Nevertheless, we anticipated such criticisms by computing not only intercoderreliability, but interinvestigator-teliability as well. After intensive training, the interinvestigator-teliability was determined by coding several Strange Situations recorded by Grossmann and Escher-Graub which had been checked by Main. The reliability between the Dutch and German coders for the most important interactive scales (proximity seeking', 'contact maintaining', 'resistant behavior', and 'avoidant behavior') ranged from .77 to .96 . Agreement at the level of classification was very high: 18 cases were classified and only one case led to a difference of opinion.

The quality of attachment was determined on the basis of four interactive scales ('proximity seeking', 'maintaining contact', 'resistance', and 'avoidance') in the two reunion episodes, and also on the basis of notes on the behavior of the children in the other episodes. The intercoder agreement $(n=22)$ for the classification was $96 \%$; for the subgroups $91 \%$. Afterwards, the tapes were analyzed, and all other episodes and a few other behaviors ('search', 'distance interactions', 'crying', and 'exploration') were coded as well. These variables were measured to describe the behavior of the children in the Strange Situation in addition to the variables used in the classification. The intercoder-reliability for the interactive scales including 'search' and 'crying' ranged from .73 to .97 . Agreement for 'exploratory manipulation' was $78 \%$, for 'exploratory locomotion' $55 \%$, the latter behavior was not included in the analysis.

\section{Validity}

In attachment theory the relationship between quality of attachment and sensitivity of the mother can be considered as an indication of the validity of the Strange Situation. In two free-play sessions of $4 \mathrm{~min}$. each, the sensitivity of a subsample of 24 mothers

${ }^{3}$ F. A. Goossens, The quality of the attachment relationship of two-year-old children of working and nonworking mothers and some associated factors. (Unpublished manuscript, University of Leiden, Department of Education, 1985) 
to signals from their children was assessed, using a nine-point rating scale derived from the work of Ainsworth, Bell, and Stayton (1974). The mothers were asked to play with their children in their usual way. A mother received a high score on this scale if she perceived and interpreted the signals from her baby correctly and responded to them promptly and appropriately. Her responses had to be temporally contingent to the signals from the child. A mother received a low score if she tended to distort the baby's signals and adopted them to her own wishes and defensive mechanisms or did not react at all to the communicative behaviors of the child. The intercoder-reliability for this rating scale was .83 . Coders were blind to classification of patterns of attachment in the Strange Situation.

The scores for the two sessions were added, with scores ranging from 2 to 18 . The mean scores for the mothers of B-children ranged from $11.0(\mathrm{~B} 1, n=4)$ to 14.3 $(\mathrm{B} 3, n=3)$. Mothers of B4-children scored 12.5 $(n=6)$. The mean scores of mothers of A-children $(n=4)$ and C-children $(n=4)$ were 10.5 and 9.0, respectively. The differences between the mean scores of the anxiously and securely attached mother-child pairs are an indication for the validity of the Strange Situation ptocedure. ${ }^{3}$

\section{RESULTS}

\section{Basic Scores}

The Strange Situation procedure presented no special problems in the Dutch sample. Only rarely did we have to interrupt an episode because a mother judged the situation too stressful for her child. The children were somewhat older (mean age $21 \mathrm{mo}$.) than the children for whom the Strange Situations has been developed (12 to $18 \mathrm{mo}$.). But several other authors used the procedure sucessfully with 2-yr.-olds and even older children (Blehar, 1974; Ragozin, 1980). Although older children show more distance interaction, no clear age effects were found in the over-all relationships between variables and children as depicted below in Fig. 2.

The mean scores on the interactive scales in the American sample of Ainsworth, et al. (1978) were the same or somewhat higher than those in our sample, except for avoidant behavior, which was more predominant for the Dutch children. The differences were small: the mean difference for the interactive scores (without 'avoidance') in Episode 4 to 8 was .45 , less than onehalf a scalepoint. The Dutch children had means of 3.2 and 2.8 on 'avoidance' towards the mother in Episodes 5 and 8. For the American children these were 2.8 and 2.6 , respectively.

The mean scores on the interactive scales only partly determine the quality of attachment, which is derived from patterns of attachment behaviors. The Dutch distribution of mother-child pairs over attachment categories differed rather strongly from the American distribution; see Table 1.

The percentages of $\mathrm{B} 4$ - and $\mathrm{C}$-children are rather conspicuous. We shall not dwell on the possible causes of these fairly large cross-cultural differenceswhich in different forms were also found in studies in Japan, Israel, Germany, and Sweden. We restrict ourselves to the characteristics of the B4 category. 
TABLE 1

Distribution of AtTACHMENT CATEgories

\begin{tabular}{|c|c|c|c|c|c|}
\hline \multirow{2}{*}{$\begin{array}{c}\text { Attachment } \\
\text { Category }\end{array}$} & & \multicolumn{2}{|c|}{ Netherlands* } & \multicolumn{2}{|c|}{ USA† } \\
\hline & & $\bar{f}$ & $\%$ & $f$ & $\%$ \\
\hline Anxious-avoidant & A & 33 & 24 & 23 & 21 \\
\hline \multirow[t]{4}{*}{ Secure } & $\mathrm{B} 1$ & 35 & 26 & 10 & 9 \\
\hline & $\mathrm{B} 2$ & 21 & 15 & 11 & 10 \\
\hline & B3 & 20 & 15 & 45 & 42 \\
\hline & B4 & 22 & 16 & 4 & 4 \\
\hline Anxious-resistant & $\mathrm{C}$ & 5 & 4 & 13 & 13 \\
\hline Total & & 136 & 100 & 106 & 100 \\
\hline
\end{tabular}

*Goossens (1985): 21-mo.-old children.

†Ainsworth, et al. (1978): 12-mo.-old children.

\section{Interactive Scales}

First we describe the behavior of the B4-children in the Strange Situation. In Table 2 the mean scores of the attachment categories on the interactive scales used for the classification are given. Differences between means were tested for significance using the Student-Newman-Keuls multiple-range test; see Table 3.

TABLE 2

MEAN SCORES OF ATTACHMENT CATEgoRIES ON INTERACTIVB SCALES

\begin{tabular}{|c|c|c|c|c|c|c|c|c|c|}
\hline \multirow{3}{*}{$\begin{array}{l}\text { Attachment } \\
\text { Category }\end{array}$} & \multicolumn{8}{|c|}{ Interactive Behaviors* } & \multirow[t]{3}{*}{$n$} \\
\hline & \multicolumn{2}{|c|}{ Proximity } & \multirow{2}{*}{\multicolumn{2}{|c|}{$\begin{array}{c}\text { Contact } \\
\text { maintaining } \\
\end{array}$}} & \multicolumn{2}{|c|}{ Resistance } & \multicolumn{2}{|c|}{ Avoidance } & \\
\hline & $M_{5}$ & $\overline{M_{s}}$ & & & $M_{\bar{s}}$ & $M_{s}$ & $M_{5}$ & $M_{8}$ & \\
\hline A & 2.2 & 1.9 & 1.1 & 1.2 & 1.7 & 2.9 & 4.0 & 4.5 & 33 \\
\hline B1 & 2.2 & 2.1 & 1.1 & 1.1 & 1.5 & 1.6 & 3.1 & 2.9 & 35 \\
\hline B2 & 2.6 & 4.1 & 1.3 & 2.4 & 1.3 & 1.7 & 3.7 & 2.2 & 21 \\
\hline B3 & 3.2 & 3.9 & 1.9 & 2.9 & 1.3 & 1.3 & 1.6 & 1.6 & 20 \\
\hline B4 & 3.7 & 5.2 & 2.5 & 5.0 & 2.3 & 3.2 & 2.7 & 2.0 & 22 \\
\hline C & 3.6 & 5.8 & 1.6 & 4.8 & 3.2 & 3.8 & 3.8 & 1.6 & 5 \\
\hline Total $M$ & 2.7 & 3.3 & 1.5 & 2.4 & 1.7 & 2.2 & 3.2 & 2.8 & 136 \\
\hline$S D$ & 1.4 & 1.9 & 1.1 & 2.0 & 1.0 & 1.3 & 1.5 & 1.4 & \\
\hline
\end{tabular}

${ }^{*} M_{s}=$ Episode 5, $M_{s}=$ Episode 8 (Goossens, 1985).

The similarity between the $\mathrm{B} 4$ and the $\mathrm{C}$ category and the relative large difference with the other $\mathrm{B}$ categories is striking. In Episodes 5 and 8, B4and C-children show the most intense 'proximity seeking', 'contact maintaining', and 'resistant behavior'. In the final reunion Episode 8, these differences were statistically significant, in spite of the small number of C-children. The only similarity between B4 and the other B groups seems to be the amount of 
TABLE 3

Multiple-Range Tests for Differences Betwenen Mean Scores of ATTACHMENT CATEGORIES ON THE INTERACTIVE SCALES

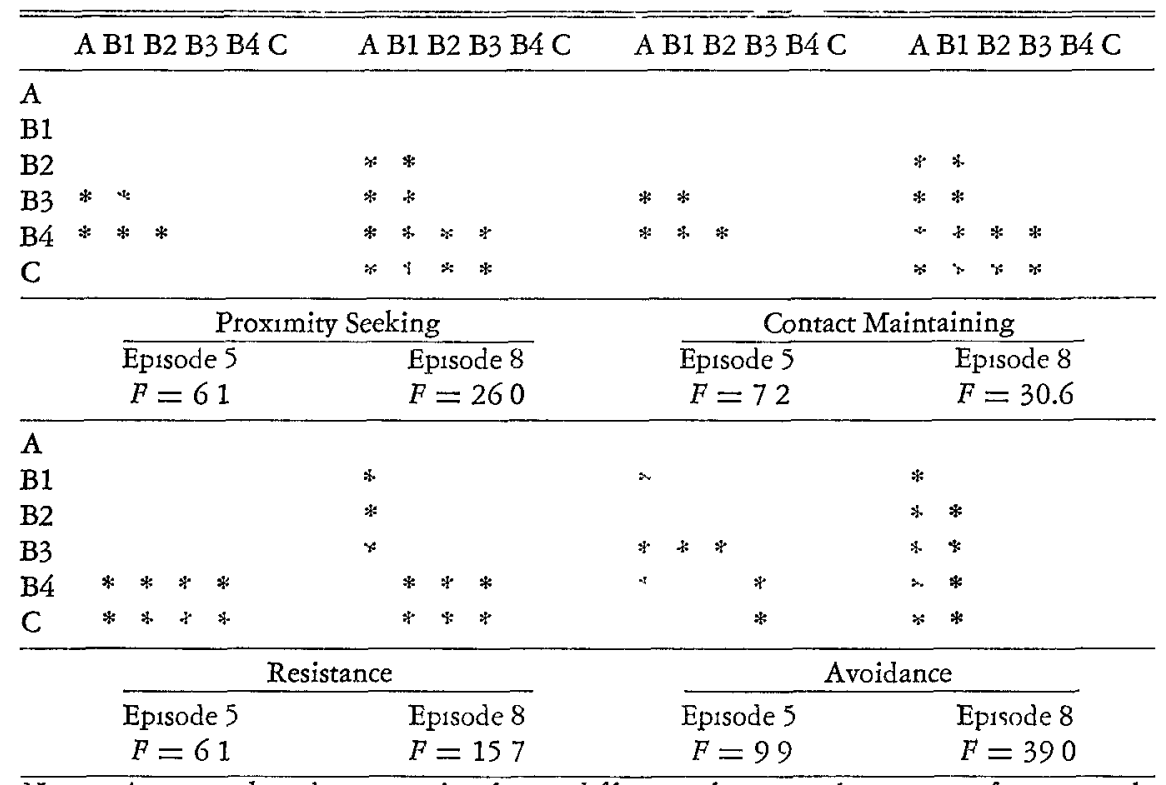

Note-An asterisk indicates a significant difference between the means of two attachment categories $(p<05)$. $p<001$ for all $F$ tests

'avoidant behavior' shown The differences between $B 4$ and $C$ were not significant. There was, however, a clear trend towards more intensive 'resistant behavior' of the C-children towards the mother 'Resistance' is the decisive element in classifying children in the C-category. So far the analyses focussed on a corroboration of the classification procedure In the following paragraphs, variables not used to classify the children, such as 'search', 'distance interaction', 'crying', and 'exploration', have been included to describe the (sub-) groups.

\section{Exploration}

The Strange Situation was developed to get some insight into the attachment-exploration balance of young children in stressful circumstances The way in which the balance is redressed in the presence of the caregiver indicates the quality of the relationship with the caregiver Securely attached children may be somewhat upset when a stranger enters after the caregiver has left. They may be somewhat upset when reunited with the calegiver and show a tendency to cling. But shortly afterwards exploration and play quickly supersede 'proximity seeking' and 'contact maintaining'. Especially for anxiously 
attached children, the caregiver, however, is not the safe base from which to explore the environment. Anxiously avoidant children seem to explore their environment under nearly all circumstances but in a rather superficial way. Once disturbed, anxiously resistant children stop exploring, despite the presence of their caregiver. The question arises, then, whether the attachment-exploration balance of B4-children redresses itself in the same way as with securely attached children. Fig. 1 shows a diagram for 'exploratory manipulation' across episodes and attachment categories The differences between categories were tested for significance with the Student-Newman-Keuls multuple-range tests The results of the over-all analysis of variance and of the multiple-range tests are summarized in Table 4.

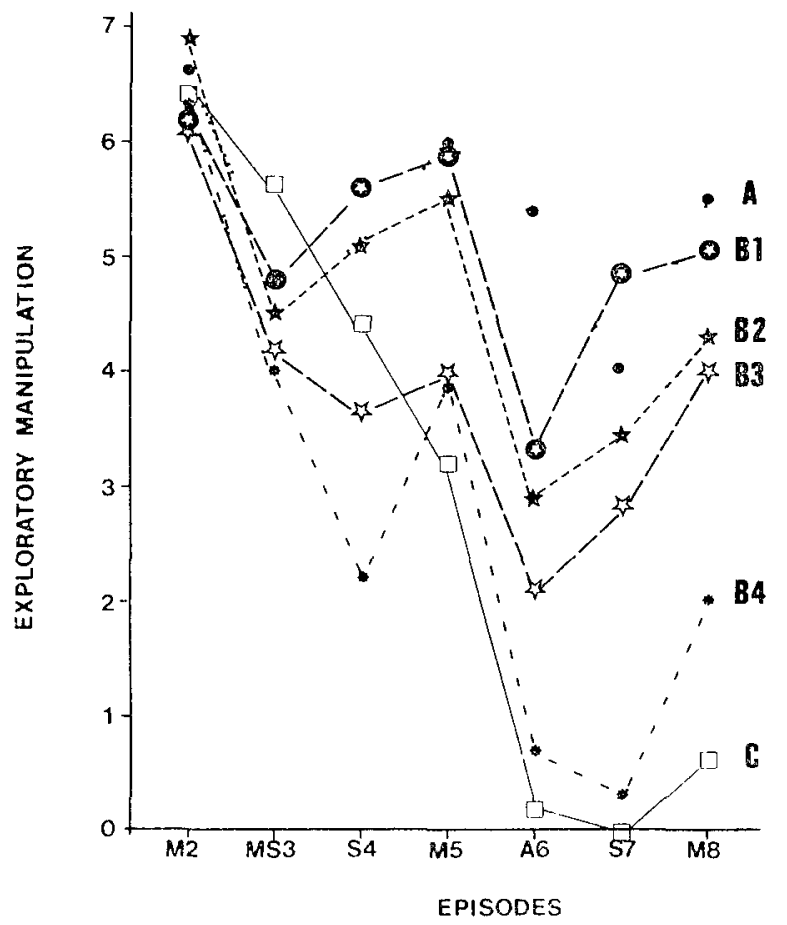

FIG 1. Exploratory manipulation per attachment category and episode

Initially, the categories do not differ in the number of time-intervals devoted to 'exploratory manipulation' There seem to be no initial differences between categories in level of activity as an indication of temperamental characteristics The fanning out of the categories in later episodes seems to be caused by the increasing stress of the Strange Situation. From the fourth episode onwards, in which the child remains alone with the stranger, the B4 cate- 
TABLE 4

MULTTPLE-RANGE TeSTS FOR DIFFERENCES IN EXPLORATORY MANIPUlation PER ATTACHMENT CATEgORY

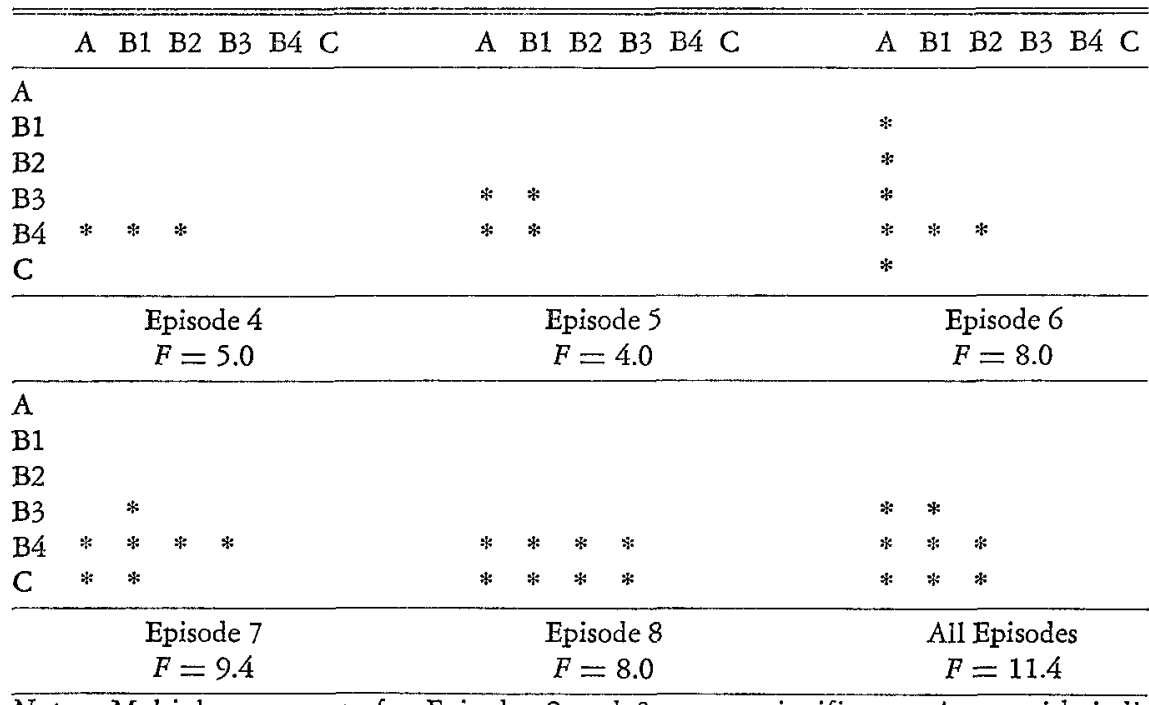

Note--Multiple-range tests for Episodes 2 and 3 are nonsignificant. An asterisk indicates a significant difference between the means of two attachment categories; $p<.002$ for all $F$ tests.

gory begins to explore less and less. Gradually, the C-children join the $\mathrm{B} 4$ group. Their attachment-exploration balance is strongly affected and is not even redressed in the last episode in which the mother is present again. This is in sharp contrast with the other B-children. On the other hand, the anxiously avoidant children never cease to explore.

Judging by exploration alone, it seems doubtful whether B4 can be considered securely attached, without violating the essence of secure attachment. The caregiver has to be able to reassure securely attached children, even at moments of stress and anxiety, and to stimulate exploration.

\section{Profile of $B 4$ in the Strange Situation}

One way of describing a multitude of bebaviors of a number of people across episodes of the Strange Situation is by means of a three-mode principal component analysis (Tucker, 1966). Elementary descriptions of the method can be found in Levin (1965) or Kroonenberg (1983, Chapter 2). In such a procedure principal component analyses on each of the three modes, i.e., children (136), variables (15), and 'phases' (2), are performed simultaneously. Each of the two phases consists of a pair of episodes. Phase 1 consists of Episodes 4 and 5, and Phase 2 of Episodes 7 and 8. In total, scores 
on 15 variables per phase are available: 5 interactive scales, 'crying' and 'exploration' both towards the stranger and the mother plus 'searching' for the mother in Episode 4 and 7. This way the children's behavior towards the stranger can also be described and the relationship between the interactive behaviors towards the stranger and towards the mother can be characterized. 'Exploratory manipulation' and 'crying' in presence of the mother and of stranger can be included too. It should be noted that the present analyses are based upon much more information than is used in the classification procedure. The profile is, therefore, not only a corroboration of this procedure but also an extension of the description of the (sub-) groups as they behave in the experimental setting.

The assumption that behavior measured by the same variables in Episodes 4 and 7 and in 5 and 8 can be considered equivalent, forms the basis for the construction of two phases. Furthermore, the same interactive behaviors are essentially different when directed towards the stranger or towards the mother. This is contrary to the assumption of a preliminary analysis (Kroonenberg, 1985).

A solution with two components each for the children's mode and for the variable mode, and only one for the episode mode, fitted $44.3 \%$ of the total variation or sum of squares. Because the analysis (but not always the classification) presupposes a linear model, we weighted the antithetical behaviors towards the mother in Episodes 5 and 8 with $2 / 3$ and 4/3, respectively, to accentuate the differential importance of Episode 8 for the classification.

We now focus the description of the results on a combined plot of children and variables in which the children are labelled according to their attachment category. We start by describing the two components of the scales. The $X$-axis (36.6\% explained variation) is characterized by dependent behavior, such as persistent 'crying' in the presence of mother and stranger, 'contact maintaining' mixed with some 'resistant behavior', and combined with considerable stranger-anxiety. The negative pole is characterized by positive 'distance interaction' to the stranger, and by considerable 'exploration' in presence of both stranger and mother. This axis could be called the exploration-dependency dimension.

The positive pole of the $Y$-axis ( $7.7 \%$ explained variation) is characterized by antithetical interactive behavior towards the mother ('avoidance' and to a lesser extent 'resistance'). The negative pole is characterized by positive interaction with the mother ('proximity seeking', 'distance interaction', 'search'). In contrast, the behavior towards the stranger is more positive, as the interaction with the mother is more negative, and vice versa. This component could be called the avoidance-positive interaction dimension. In spite of the relatively high loadings of some variables on both components the un- 


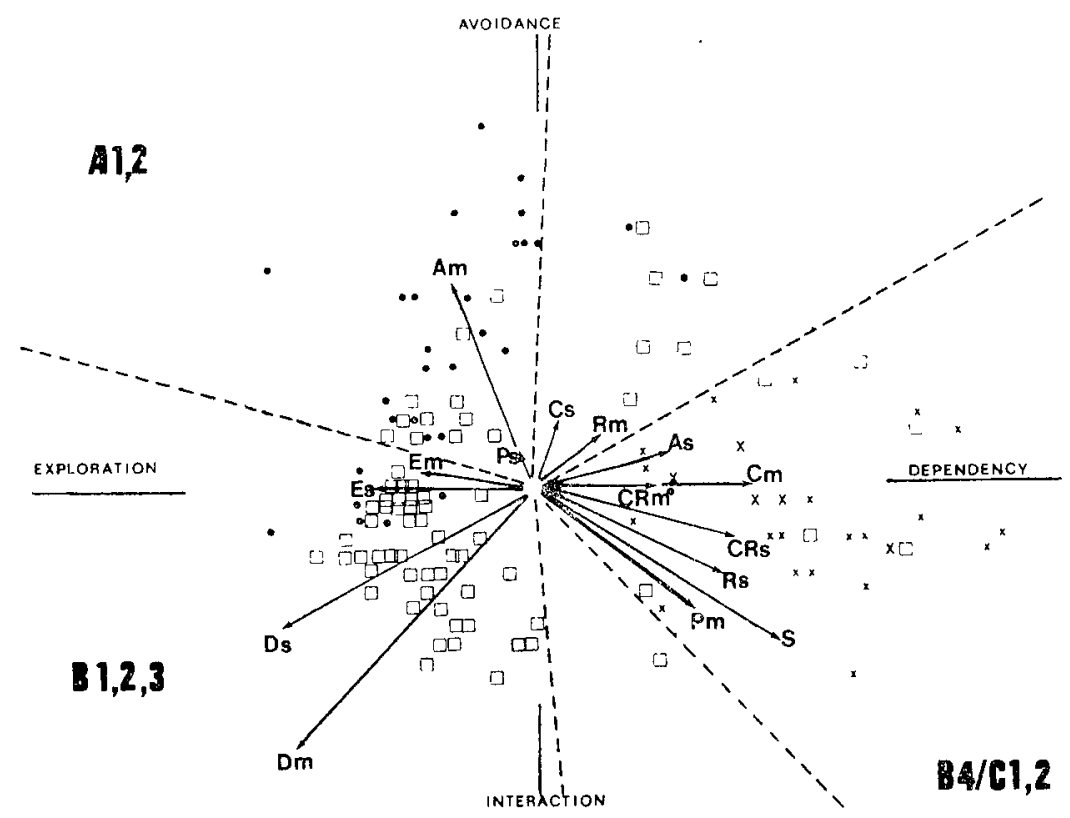

FIG. 2. Combined plot of variables and children based on a three-mode principal component analysis. (Children are labelled with their attachment category: A 1, 2; $\square \mathrm{B} 1,2,3 ; \times \mathrm{B} 4 ; \times \mathrm{C} . \quad A=$ avoidance; $\mathrm{C}=$ contact maintaining; $\mathrm{CR}=$ crying; $\mathrm{D}=$ distance interaction; $\mathrm{E}=$ exploratory manipulation; $\mathrm{P}=$ proximity; $\mathrm{R}=$ resistance; $\mathrm{S}=$ search, $s=$ behavior towards the stranger, $m=$ behavior towards the mother.)

rotated solution seemed to be most adequate. It is clear that complex behavioral systems of children in stressful circumstances can only roughly be decomposed into a few dimensions.

Given these interpretations of the variables, we can turn our attention to the way the variables differentiate between the children. Twelve children with less than $10 \%$ fit are not shown in the figure. The interpretation of the relationships between children and variables rests on the size and sign of the projections of children on the variable vectors. Projections on the positive side of the vector (the only side depicted) represent a score above the mean on that variable. Projections on the negative side represent a score below the mean.

B4- and C-children are rather isolated from the other children, but are strongly mixed. The $\mathrm{few} B \mathrm{Bs}$ in the $\mathrm{B} 4 / \mathrm{C}$ segment belong to the $\mathrm{B} 3$ category. The $\mathrm{B} 4$ and $\mathrm{C}$ categories can be characterized by a relatively high percentage of dependent behavior such as 'crying' and clinging, mixed with relatively positive interactions with the mother and extremely negative reactions to the stranger. They show almost no 'avoidant behavior' and still less 'exploratory behavior' and 'distance interaction'. The differences with $A$ and $B 1,2,3$ are 
large, with a few exceptions. A and B1, 2, 3 are two overlapping sets, with overlap especially between B1 and A2; see also Ainsworth, et al. (1978). The avoidant children are not only characterized by strongly 'avoidant behavior' towards the mother but also by a relatively intensive 'exploration'. We did not measure the quality of this exploratory behavior. The securely attached children, B1, 2, 3 are mainly projected onto the exploration-positive interaction segment of the figure. They combine positive interaction with mother and stranger with an undisturbed exploration of the environment in the presence of the mother as well as the stranger.

Using a three-mode principal component analysis we could sketch a comprehensive profile of the B4 category and depict the relationship between the 15 variables in the four most important episodes of the Strange Situation. Because the number of C-children was small, and they show affinity to B4, it was not possible to separate the two groups in the combined plot. But it is important to realize that scores on 'resistance' towards the mother in the second reunion episode are decisive for classifying a child as $\mathrm{C}$. We found a substantial difference between the means of scores on 'resistance' of B4 and C. In the $\mathrm{C}$ category anxious-resistant behavior is dominating, while in the $\mathrm{B} 4$ category anxious-dependent behavior is predominant.

\section{DisCUSSION AND CONCLUSIONS}

The Dutch sample contains relatively few anxious-resistant children and a relatively high number of B4-children. The B4 category could be described in terms of quick and intensive activation of the attachment behavioral system in the stressful part of the Strange Situation. B4-children show relatively intensive 'proximity seeking' and 'contact maintaining' towards the mother but some 'resistant behavior' as well. They also show much anxiety about a stranget. Their attachment-exploration balance seems to be disturbed after a few episodes and hardly to redress in the presence of the mother. With respect to 'exploration', B4-children behave similar to those in the C-category, with which they differ on 'resistance' to the mother. We should like to call the B4-children dependently attached (Sagi, et al., in press). They behave dependently towards the mothers, i.e., cling to her, protest against her leaving, show intensive 'search behavior' after she has left. They are also conspicuous by the virtual absence of 'exploratory behavior' (Beller, 1955) and are anxious in the presence of a stranger or when alone in a strange environment.

The question to be solved is whether B4 is really part of the B-group. Ainsworth, et al. (1978) underlined the borderline status of B4 and demanded more research to solve the problem definitively. According to Ainsworth, et al. (1978), Bell (1970) counted the B4-children as securely attached, because their mothers appeared to be as sensitive as most B-mothers are; yet it does not seem logical to classify children only on the basis of their mothers' 
behavior. In our study, mothers of B4-children did appear to be very sensitive to signals of their children in a free-play situation. In addition, Escher-Graub, and Grossmann ${ }^{4}$ showed that there is a difference between the sensitivity of mothers of B4-children, and those of B2-, 3-children. The B4-mothers were rather insensitive to weak verbal initiatives of the child but, on the other hand, rather sensitive to physical contact seeking. Mothers of B2-, 3-children were sensitive to verbal initiatives as well.

The mixture of anxious-resistant and secure attachment behaviour of B4 could possibly be explained by the cumulative character of attachment development. The discussions on the stability of attachment (Thompson, Lamb, \& Estes, 1983; Waters, 1983; Lamb, et al., 1984) showed that an attachment relationship, once formed, can be influenced by environmental changes. The quality of attachment is said to be predictably unstable (Waters, 1983; Vaughn, et al., 1979). Against this background it becomes necessary to study in more detail bybrid children, i.e., those children who went through more than one attachment category in the course of their development. Viewing development as a cumulation of experiences in which the shadows of the earlier adaptation remain' (Sroufe, 1983), a C-child with a B-history could react differently in stressful circumstances from a C-child with a continued C-history. Our hypothesis concerning the $\mathrm{B} 4$ category is, then, that these dependent children used to belong to the securely attached group, but after (physical) separation now display an anxious-attachment pattern with some residue of their past status. This hypothesis can only be tested in longitudinal research in which changes in caregiving arrangement and attachment classification are carefully monitored.

\section{REFERENCES}

AINSWORTH, M. D. S., BELL, S. M., \& STAYTON, D. J. Infant-mother attachment and social development: 'socialisation' as a product of reciprocal responsiveness to signals. In M. P. Richards (Ed.), The integration of a child into a social world. London: Cambridge Univer. Press, 1974. Pp. 99-135.

Ainsworth, M. D. S., BlehaR, M. C., WATERS, E., \& WALl, S. Patterns of attachment: a psychological study of the Strange Situation. Hillsdale, NJ: Erlbaum, 1978.

AINSWORTH, M. D. S., \& WITTIG, B. A. Attachment and exploratory behavior of oneyear olds in a strange situation. In B. M. Foss (Ed.), Determinants of infant bebavior. Vol. 4. London; Methuen, 1969. Pp. 111-136.

BELI, S. M. The development of the concept of objects as related to infant-mother attachment. Child Development, 1970, 41, 291-311.

Beller, E. K. Exploratory studies of dependency. Transactions: New York Academy of Sciences, 1959, 21, 414-426.

BlEHAR, M. C. Anxious attachment and defensive reacting associated with day care. Child Development, 1974, 45, 683-692.

${ }^{4}$ C. Escher-Graub \& K. E. Grossmann, Bindungsunsicherheit im zweiten Lebensjahr. Die Regensburger Querschnittuntersuchung. (Unpublished manuscript, Universität Regensburg, Institut für Psychologie, 1983). 
CONNELL, D. B. Individual differences in attachment behavior: long term stability and relationship to language development. Unpublished doctoral dissertation, Syracuse Univer., New York, 1977.

HAZEN, N. L., \& DURRETT, M. E. Relationship of security of attachment to exploration and cognitive mapping abilities in 2-year-olds. Developmental Psychology, 1982, $18,751-759$.

KROONENBERG, P. M. Three-mode principal component analysis: theory and applications. Leiden: DSWO Press, 1983.

KROONENBERG, P. M. Three-mode principal component analysis illustrated with an example from attachment theory. In H. G. Law, C. W. Snyder Jr., J. Hattie, \& R. P. McDonald (Eds.), Research metbods for multi-mode data analysis. New York: Praeger, 1985. Pp. 64-103.

LAMB, M. E., Thompson, R. A., GaRdneR, W., Charnov, E. L., \& Estes, D. Security of attachment as assessed in the Strange Situation: its study and biological interpretation. Bebavioral and Brain Sciences, 1984, 7, 127-147.

LEvin, J. Three-mode factor analysis. Psychological Bulletin, 1965, 64, 442-452.

RAGOZIN, A. R. Attachment behavior of day-care children: naturalistic and laboratory observations. Cbild Development, 1980, 51 , 409-415.

SAGI, A., LAMB, M. E., LEWKowicz, K. S., ShohAM, R., DVir, R., \& Estes, D. Security of infant-mother, -father, and -metapelet attachments among Kibbutzreared Israeli Children. In I. Bretherton (Ed.), The Strange Situation: new directions for research. Monographs of the Society for Research in Child Development, in press.

SROUFE, L. A. Infant-caregiver attachment and patterns of adaptation in preschool: the roots of maladaptation and competence. In M. Perlmutter (Ed.), Minnesota symposia in child psychology. Vol. 16. Hillsdale, NJ: Erlbaum, 1983. Pp. $41-91$.

THOMPSON, R. A., LAMB, M. E., \& EsTes, D. Stability of infant-mother attachment and its relationship to changing life circumstances in an unselected middle-class sample. Child Development, 1982, 53, 144-148.

Tucker, L. R. Some mathematical notes on three-mode factor analysis. Psychometrika, $1966,31,279-311$.

VAN IJZendoorn, M. H., TAvecchio, L. W. C., Goossens, F. A., Vergeer, M. M., \& SWAAN, J. How B is B4?. Attachment and security of Dutch children in Ainsworth's Strange Situation and at home. Psycbological Reports, 1983, 52, 683-691.

VAN WESTERLAAK, J. M., KROPMAN, J. A., \& COLLARIS, J. W. M. Beroepenklapper. Nÿmegan: Institute for Applied Sociology, 1975.

VAughN, B., Egeland, B., SRoufe, L. A., \& WATERs, E. Individual differences in infant-mother attachment at twelve and eighteen months: stability and change in families under stress. Child Development, 1979, 50, 971-975.

WATERS, E. The stability of individual differences in infant attachment: comments on the Thompson, Lamb and Estes contribution. Cbild Development, 1983, 54, 516-520.

Accepted June 12, 1985. 